\title{
EFEITO DO CÁLCIO SOBRE AS CARACTERÍSTICAS ANATÔMICAS DE RAÍZES DE MILHO (Zea mays L.) "SARACURA" BRS-4154 SUBMETIDO AO ALAGAMENTO EM CASA DE VEGETAÇÃO
}

\author{
JORGE LUIS ROMERO FERRER ${ }^{1}$, EVARISTO M. DE CASTRO², JOSÉ D. ALVES², MARCO ANTONIO \\ ALEANCAR $^{3}$, SILVANA DA SILVA ${ }^{3}$, CARLOS VINICIUS VIEIRA $^{4}$, PAULO CÉSAR MAGALHÃES 5 \\ ${ }^{1}$ Corporação Colombiana de Investigação Agropecuária CORPOICA - Colômbia. E-mail:jorgeromeroferrer@yahoo.com \\ ${ }^{2}$ Prof. do Departamento de Biologia, Universidade Federal de Lavras. Caixa Postal 37, CEP. 37200-000 Lavras, MG. \\ E-mail: emcastro@ufla.br (autor para correspondência) \\ ${ }^{3}$ Pós-graduando, MS, Universidade Federal de Lavras. Caixa Postal 37, CEP. 37200-000 Lavras, MG \\ ${ }^{4}$ Estudante de iniciação cientifica da Universidade Federal de Lavras. \\ ${ }^{5}$ Pesquisador, Embrapa Milho e Sorgo. Caixa Postal 151, CEP. 35701-970 Sete Lagoas, MG. E-mail: \\ pcesar@cnpms.embrapa.br.
}

Revista Brasileira de Milho e Sorgo, v.3, n.2, p.172-181, 2004

RESUMO - O milho "Saracura" BRS-4154 apresenta-se como uma opção válida para as várzeas sujeitas ao alagamento temporário. Pesquisas têm demonstrado que a presença de $\mathrm{CaCl}_{2}$ no ambiente de germinação alagado aumenta a tolerância do milho "Saracura" a essa condição. Este trabalho foi conduzido em casa de vegetação na Embrapa Milho e Sorgo, localizada no município de Sete Lagoas - MG, com o objetivo de obter melhor conhecimento das alterações anatômicas em Milho "Saracura" BRS-4154 sob efeito de cálcio e alagamento. As plantas foram submetidas aos tratamentos com e sem adição de uma dose de $300 \mathrm{~kg} \mathrm{ha}^{-1}$ de cloreto de cálcio, incorporado em todo o solo. Cada tratamento foi avaliado em condições normais de irrigação e sob encharcamento imposto a partir do estádio V6 até a floração. O tratamento controle foi com irrigação normal e sem aplicação de cálcio. As avaliações do ensaio foram realizadas na floração. Foram retirados fragmentos de raízes de $5 \mathrm{~cm}$ de comprimento, os quais foram submetidos a técnicas clássicas em microtécnica vegetal para confecção e analise de tecidos. Foram observadas diferenças anatômicas entre os tratamentos alagado e com irrigação normal. $\mathrm{O}$ alagamento induziu, em raízes, aumento de espaços intercelulares, aumento da espessura do córtex e do cilindro vascular. Em relação à espessura da epiderme, esta foi mais espessa em condições normais. A presença de aerênquimas ocorreu somente em plantas em condições alagadas, comprovando que esses não são constitutivos desta espécie. A proporção de aerênquimas diminuiu com a aplicação de cálcio, mostrando a participação desse íon em manter a integridade da parede celular, evitando o colapso desordenado e aumentando a sobrevivência da planta em condições alagadas. A aplicação de cálcio influenciou no arranjo celular da epiderme e promoveu um menor espessamento da exoderme em condições normais de irrigação.

Palavras-chave: encharcamento, cloreto de cálcio, anatomia, milho.

\section{CALCIUM EFFECT ON ANATOMICAL CHARACTERISTICS OF THE "SARACURA" BRS-4154 MAIZE (Zea mays L.) ROOTS SUBJECT TO FLOODING IN GREENHOUSE}




\begin{abstract}
Saracura" BRS-4154 maize is an alternative for the areas subject to temporary flooding. Researches have been demonstrating that $\mathrm{CaCl}_{2}$ presence in flooded germination atmosphere increases "Saracura" maize tolerance to that condition. This work was conducted in greenhouse at Embrapa Milho e Sorgo, located in Sete Lagoas MG, with the objective of obtaining better knowledge of anatomical alterations in "Saracura" BRS-4154 maize under the effect of calcium and flooding. Plants were submitted to treatments with and without addition of $300 \mathrm{~kg} \mathrm{ha}^{-1}$ calcium chloride, incorporated in the whole soil. Each treatment was evaluated under regular irrigation conditions and under flooding imposed from stage V6 until flowering; the control treatment had normal irrigation and no calcium application. Assay evaluations were accomplished during flowering. Five to eight $\mathrm{cm}$ detached roots fragments were submitted to classic micro techniques to make and analyze tissues. Anatomical differences were observed among treatments - flooded and with normal irrigation - in relation to epidermis thickness, thicker in normal conditions. The aerenchyma presence only occurred in plants in flooded conditions, proving that those are not constituent of this species. The aerenchyma proportion decreased with calcium application, showing the participation of this ion in cell wall structure, avoiding disordered collapse and increasing the survival of the plant in flooded conditions. Calcium application influenced cellular epidermis arrangement and promoted a smaller exoderm thickness in normal irrigation conditions.
\end{abstract}

Key words: flooding, calcium, anatomy, maize.

As plantas são aeróbicas e dependem do suprimento de oxigênio molecular para respiração e demais reações de oxidação necessárias a sua sobrevivência. Sem a presença de oxigênio livre, a maioria das plantas com metabolismo ativo não sobrevivem por mais de poucas horas ou dias, não se desenvolvendo o suficiente para a reprodução da espécie (Kawase, 1987). Nos ambientes com excesso de água no solo, há um estresse pelo decréscimo da concentração de oxigênio no meio (Jackson \& Drew, 1984), afetando a nutrição mineral, a produção e alocação de reguladores de crescimento, a fotossíntese, a respiração e a alocação de carboidratos (Huang et al., 1995; Livramento et al., 2001; Purcino et al., 2001). Em decorrência da modificação de vários processos na planta, podem ser observados os seguintes danos: clorose, epinastia e abscisão de folhas, diminuição da taxa de crescimento e hipertrofia do caule, formação de raízes adventícias e/ou superficiais, redução do crescimento de raízes e formação de aerênquimas (Platzeck,
1989; Magalhães et al., 2000; Dantas et al., 2001; Alves et al., 2002). As raízes formadas em condições de excesso de água, tendem, geralmente, a: aumentar o diâmetro; reduzir os pêlos absorventes; ramificar e ter raízes curtas; aumentar o número e a dimensão de aerênquimas; diminuir o tamanho das células com o aumento da suberização e lignificação das paredes (Durbim, 1971). Baruch \& Mérida (1995) observaram alterações provocadas pela inundação, principalmente em relação à proporção de aerênquimas. Em condições controladas, estes mesmos autores observaram que as gramíneas Brachiaria mutica e Echinochloa polystachya já apresentavam grande parte do volume dos tecidos radiculares destinado a aerênquimas. Menezes Neto (1994) também observou em plântulas de açaí (Euterpe oleracea Mart.) que estas apresentaram a formação de aerênquimas mesmo em condições normais de aeração, levando-o a concluir que os aerênquimas são constitutivos nesta espécie, possibilitando, assim, que possua elevado 
grau de tolerância à baixa disponibilidade de oxigênio no solo. O estresse causado pelo alagamento reduz severamente o crescimento e a produtividade da cultura do milho, o qual é classificado como não tolerante a essa condição. No entanto, têm-se encontrado cultivares que apresentam certa tolerância à hipoxia, fato o qual tem sido atribuído à presença de diferentes mecanismos bioquímicos e fisiológicos, tais como fechamento estomático e também alterações morfológicas, como, por exemplo, a formação de raízes adventícias e aerênquima nas raízes (Drew et al., 1979; Dantas et al., 2001). A cultivar "Saracura" foi caracterizada como tolerante a períodos intermitentes de alagamento do solo, por ser menos susceptível a alterações no seu desenvolvimento vegetativo e reprodutivo (Parentoni et al., 1995). A maior tolerância à baixa pressão de oxigênio está relacionada com o metabolismo de parede celular e de cálcio, visto que este elemento atua de maneira estrutural, conferindo maior resistência a essa parede (Grant et al., 1973; Damarty et al., 1984). A função do cálcio como elemento estrutural, participando de ligações covalentes entre os grupos carboxílicos dos ácidos poligalacturônicos, constituintes da parede celular (Grant et al., 1973; Damarty et al., 1984), tem sido objeto de vários estudos, uma vez que é o único elemento que possui atividade apoplástica (Seling et al., 2000). A adição de cloreto de cálcio à solução de germinação promoveu o aumento na sobrevivência das plântulas tanto do cV "Saracura" como também da variedade BR-107 classificada como não tolerante a essa condição de estresse (Vitorino et al., 2001). Alves et al. (2002) citoram que, além de aumentar a sobrevivência, o cálcio promove alterações no desenvolvimento das plântulas de "Saracura" por reduzir o crescimento de raízes em até $37 \%$ em relação ao controle. Dantas et al. (2001) observou que, após 12 horas de hipoxia, as plântulas de "Saracura" sobreviventes apresentavam cerca de $12 \%$ da área do córtex das raízes ocupadas por aerênquimas, podendo esses espaços intercelulares chegarem a ocupar 50\% dessa área após 4 dias de estresse.

Baseados nos resultados obtidos nos trabalhos efetuados com milho "Saracura" em condições controladas de laboratório e sala de crescimento, este trabalho objetivou estudar o efeito do cálcio sobre os aspectos anatômicos de raízes de milho "Saracura" submetidas ao alagamento continuo até a floração.

\section{Material e Métodos}

O ensaio foi conduzido em regime controlado de casa de vegetação na Embrapa Milho e Sorgo, localizada no município de Sete Lagoas - MG, com altitude de $732 \mathrm{~m}$, latitude Sul 19²8', longitude Oeste $44^{\circ} 15^{\prime}$. As temperaturas máxima e mínima no interior da casa de vegetação durante o período de avaliação foram de $30^{\circ}$ a $36^{\circ} \mathrm{C}$ e $9,5^{\circ}$ a $15,5^{\circ} \mathrm{C}$, respectivamente. A umidade relativa oscilou entre $52 \%$ e $78 \%$. As sementes utilizadas foram de Milho "Saracura" BRS4154, ciclo 14; o solo empregado foi de várzea classificado como Neossolo Flúvico Tb, Eutrópico Típico, textura argilosa, fase relevo plano campos de várzea (Embrapa Solos, 1999). Foram utilizados vasos de $20 \mathrm{~kg}$ de solo, com duas plantas/vaso. A adubação do solo foi de acordo com os resultados da análise química. No momento do plantio, aplicou-se adubação básica

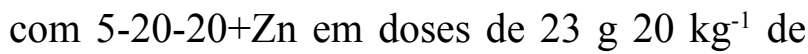
solo. Após a germinação, foram feitas coberturas semanais com sulfato de amônio em doses de

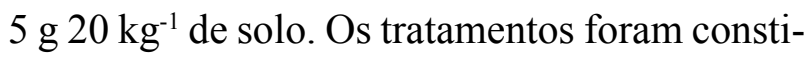
tuídos pela adição ou não de uma dose de $300 \mathrm{~kg}$ ha $^{-1}$ de cloreto de cálcio, incorporado ao solo. Cada tratamento foi avaliado em condições normais 
de irrigação e sob encharcamento imposto a partir do estádio V6 até a floração. O tratamento controle constituiu-se de irrigação normal e sem aplicação de cálcio. As avaliações do ensaio foram realizadas na floração. Raízes foram removidas do solo e lavadas com água corrente e retirados fragmentos de $5 \mathrm{~cm}$ de comprimento, os quais foram fixados em formaldeido, ácido acético e álcool etílico, F.A.A. 70\%, por 72 horas e posteriormente conservados em álcool etílico $70 \%$, segundo Johansen (1940). Os cortes transversais foram realizados a mão livre com auxilio de uma lâmina de barbear e submetidas ao processo de coloração com safra-blau, uma mistura de safranina com azul de astra (Bukatsh, 1972). A montagem das lâminas foi feita com água glicerinada e as fotomicrografias obtidas em fotomicroscópio Olympus BX-60. As determinações da espessura da epiderme e córtex, além do diâmetro do cilindro vascular da raiz, foram efetuadas através de medições realizadas nas seções transversais de lâminas semipermanentes, com auxilio de ocular micrométrica, em quatro plantas por tratamento e medidas em locais distintos de cada posição da planta.

A porcentagem da área dos espaços intercelulares (aerênquimas) nos cortes foi estimada, utilizando-se fotocópias das fotomicrografias e determinando-se a relação entre o peso da área dos espaços intercelulares e o peso da área total do córtex.

Os dados obtidos foram submetidos a análises de variância e as médias separadas pelo teste Scott-Knott a 5\% de probabilidade.

\section{Resultados e Discussão}

A epiderme da raiz apresentou-se uniestratificada, com células de paredes finas (Figuras 1A, 1B, 1C e 1D), tal como relatado por Esaú (1993). Entretanto, observou-se diferença nas paredes das células epidérmicas e que diferem em espessura, nos tratamentos com irrigação normal (Figuras 1A e 1B) quando comparados com as condições alagadas (Figuras 1C e 1D). Esses resultados foram quantificados (Tabela 1), observando-se um ligeiro decréscimo nos tratamentos em que foi aplicado o cálcio (Figuras 1B e 1D).

Nas raízes do tratamento com irrigação normal sem cálcio, foram observadas células mais heterodiamétricas na epiderme (Figura 1A) sendo também mais espessa que nas raízes que receberam os outros tratamentos (Tabela 1). Quando foi aplicado cálcio, essas mesmas células (epiderme) formaram uma camada mais compacta, variando no tamanho e arranjo em relação às raízes das plantas que receberam cálcio (Figuras 1B e 1D). Deduz-se, assim, a possibilidade de existir uma influência desse íon no arranjo celular.

Notam-se ainda, nas Figuras 1A, 1B, 1C, e $1 \mathrm{D}$, as diferenças anatômicas entre os tratamentos em relação às camadas mais externas do córtex. As raízes desenvolveram um tecido especializado, a exoderme, abaixo da epiderme uniseriada, com diferenças entre os tratamentos. As raízes do tratamento com irrigação normal e sem cálcio (Figura 1A) apresentaram as três primeiras camadas de células do córtex com células heterodiamétricas e com espessamentos de lignina e/ou suberina nas paredes das células parenquimáticas mais espessas, quando comparadas com os demais tratamentos. Seago \& Marsh (1989), estudando o desenvolvimento de raízes adventícias em Thypha glauca com ênfase na descrição da exoderme, relataram que este tecido constitui uma proteção mecânica para controle do fluxo hídrico nas raízes, tendo como principal função a proteção das células do córtex contra um colapso e contra a dissecação. Esse 
espessamento participa, assim, de uma estratégia para a sobrevivência em condições adversas de disponibilidade hídrica (Hays et al., 1991; Huang \& Fry, 1998; Silva et al., 2003).

O tratamento com irrigação normal e presença de cálcio (Figuras 1B e 1F) resultou em uma exoderme menos espessa quando comparada a do controle (Figuras 1A e 1E). Para Subaiah et al. (1994), a aplicação exógena de cálcio promove um aumento nos níveis desse elemento na parede celular e citosol. De acordo com Alves et al. (2002), o aumento dos níveis de cálcio pode levar a um acúmulo desse elemento nas células da exoderme, reforçando suas paredes e conferindo-lhes maior resistência. Desse modo, supõese que o cálcio pode promover uma redução no gasto de energia para a produção de lignina e/ou suberina. Esse acúmulo pode exercer o mesmo papel estrutural da camada lignificada do tratamento controle. Nos tratamentos alagados com e sem cálcio (Figuras $1 \mathrm{H}$ e $1 \mathrm{G}$ ), nas mesmas camadas da exoderme, este revestimento não foi tão marcante como nos tratamentos com irrigação normal. Em condições de alagamento sem cálcio (Figura 1G), as células apresentaram-se com mais espaços intercelulares e maior espessura quando comparadas as do tratamento alagado com cálcio (Figura 1H e Tabela 1).

As células da exoderme no tratamento alagado sem cálcio (Figura 1G) apresentaram pouca lignificação, o que não ocorreu no tratamento alagado com cálcio (Figura 1H). Supõese que isso ocorra, neste tratamento, em função das condições de excesso de água a que as plantas foram submetidas, indicando que as mesmas não necessitam gastar energia com produção de lignina e/ou suberina, ou seja, elas não necessitam se proteger contra a dissecação.

Observa-se que, de maneira geral, as raízes das plantas apresentaram diferenças no córtex (Tabela 1); no entanto as que receberam irrigação normal sem e com cálcio (Figuras 1I e $1 \mathrm{~J})$ não apresentaram aerênquimas, quando comparadas com aquelas sob os tratamentos

TABELA 1. Espessura da epiderme e córtex, diâmetro do cilindro vascular em micrômetro e porcentagem de aerênquimas em raízes de milho "Saracura" na época de floração, submetidas ao alagamento e aplicação de cálcio. Lavras, MG, 2003.

\begin{tabular}{ccccc}
\hline Tratamentos & $\begin{array}{c}\text { Espessura da } \\
\text { epiderme }\end{array}$ & $\begin{array}{c}\text { Espessura do } \\
\text { córtex }\end{array}$ & $\begin{array}{c}\text { Espessura do } \\
\text { cilindro vascular }\end{array}$ & $\begin{array}{c}\% \\
\text { Aerênquima }\end{array}$ \\
\hline 1 & $27,083 \mathrm{a}$ & $652,50 \mathrm{~b}$ & $1931,25 \mathrm{a}$ & 0,0 \\
2 & $23,333 \mathrm{~b}$ & $790,35 \mathrm{a}$ & $2043,75 \mathrm{a}$ & 0,0 \\
3 & $19,167 \mathrm{c}$ & $733,13 \mathrm{a}$ & $2576,25 \mathrm{a}$ & 13,7 \\
4 & $17,500 \mathrm{c}$ & $648,75 \mathrm{~b}$ & $2317,50 \mathrm{a}$ & 8,8 \\
\hline Média & 21,77 & 706,18 & 2217,18 & \\
CV & 10,07 & 8,14 & 14,37 & \\
\hline
\end{tabular}

Tratamentos: 1) Irrigação normal sem cálcio, 2) Irrigação normal com cálcio, 3) Alagado sem cálcio e 4) Alagado com cálcio. * As médias seguidas da mesma letra, nas colunas, não diferem significativamente entre si, pelo teste ScottKnott, a 5\% de probabilidade. 

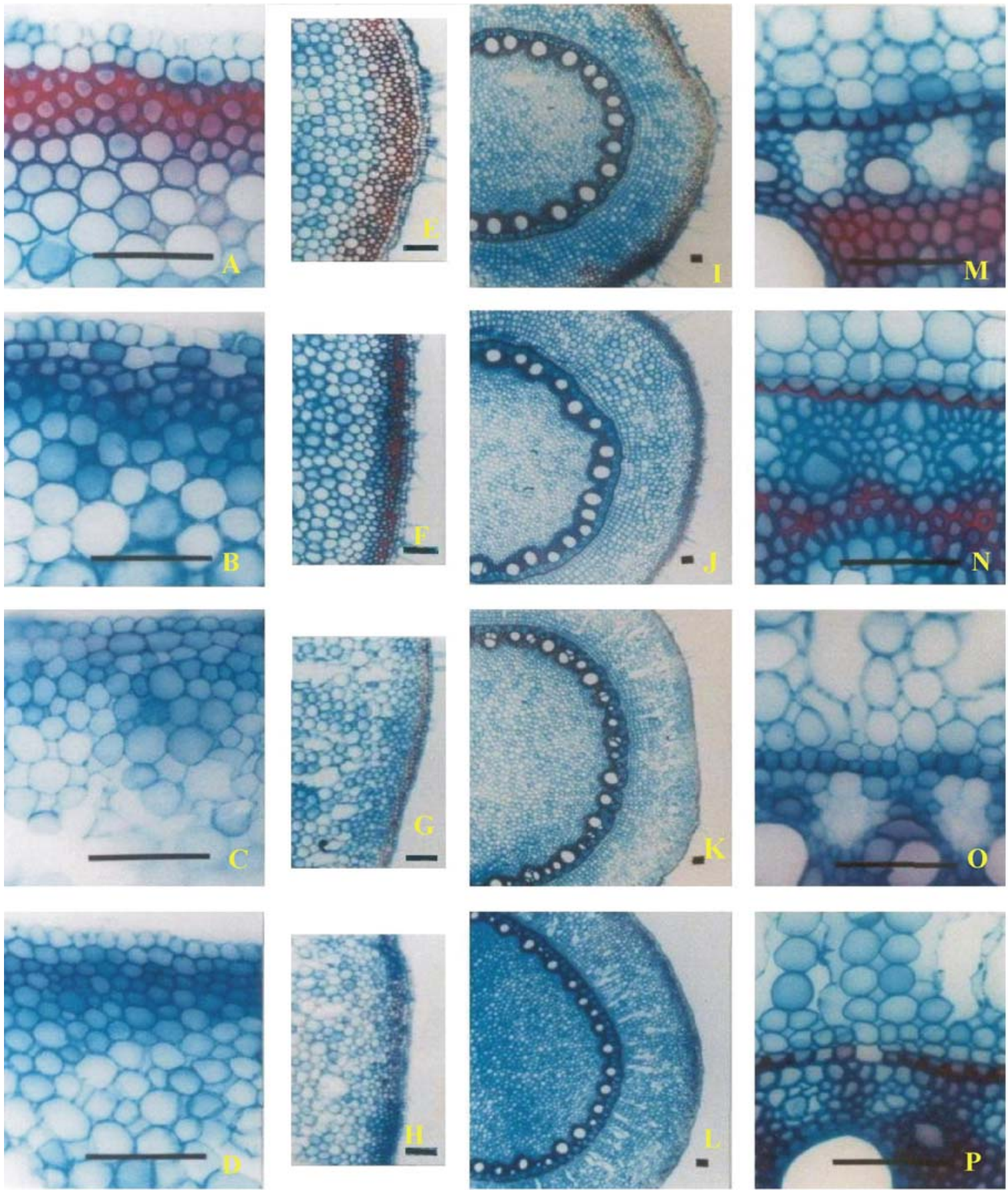

FIGURA 1. Seções transversais de raiz do milho Saracura na época de floração, submetido ao alagamento e adição de Cálcio. Lavras - MG, 2003. Barras $=100 \mu \mathrm{m}$.

1A a 1D: detalhe da epiderme e córtex externo;1E a 1H: mostrando o Córtex;1I a1L: mostrando cilindro vascular;1M a 1P: detalhe da endoderme.

Primeira linha: irrigação normal sem cálcio; segunda linha: irrigação normal com cálcio; terceira linha: alagado sem cálcio; quarta linha: alagado com cálcio. 
alagados (Tabela 1, Figuras 1K e 1L). Esses resultados mostram que os aerênquimas não são constitutivos desta espécie, tal como relatado por Esau (1993). Na literatura, a presença de aerênquima é caracterizada como resposta favorável das plantas à baixa oxigenação (Kawase, 1987; Baruch \& Mérida, 1995; Drew 1997; Moraes et al., 2001), uma vez que diminui a resistência da difusão do oxigênio entre órgãos aerados e não aerados (Drew, 1997). Sendo assim, confirma-se, mais uma vez, a tolerância da variedade "Saracura" ao excesso de água no solo. $\mathrm{Na}$ comparação entre os tratamentos alagados sem e com adição de cálcio (Figuras $1 \mathrm{~K}$ e 1L), observa-se uma diminuição de $36 \%$ do total de aerênquimas para o tratamento onde foi aplicado o cálcio (Tabela 1). Dantas et al. (2001), ao trabalharem com plântulas de milho "Saracura" submetidas ao alagamento e na presença de cálcio, concluíram que o cálcio é o inibidor da formação de espaços intercelulares quando aplicado exogenamente. Já Saab \& Sachs (1996) atribuem essa resposta ao fato da hipoxia provocar "desarranjos" nos componentes da parede celular. O cálcio, ao se comportar como um elemento importante na manutenção da integridade desta estrutura durante o período de hipoxia, reduz o colapso celular e o desenvolvimento de aerênquimas.

Para o tratamento alagado sem adição de cálcio, a formação de aerênquimas no córtex das raízes alcançou $13,7 \%$ do total do córtex, superando em $64 \%$ o tratamento alagado e com incorporação de cálcio ao solo (Tabela 1). Esses dados têm a mesma tendência aos encontrados por Dantas et al. (2001), os quais afirmaram que sob condições de hipoxia, o milho "Saracura" induziu o desenvolvimento de aerênquimas lisígenos tanto em raízes quanto em coleóptilo e que a aplicação de cálcio exógeno diminuiu seu desenvolvimento. As formações de aerênquimas são relatadas como uma adaptação das plantas a ambientes alagados com baixa pressão de oxigênio (Kolb et al., 1998).

Em todos os tratamentos, apresentou-se a endoderme caracterizada por faixa de Caspary, com o espessamento adquirindo forma de $\mathbf{U}$. Entretanto, apresentou certas modificações na parede. Nos tratamentos com irrigação normal sem ou com adição de cálcio (Figuras $1 \mathrm{Me} 1 \mathrm{~N}$ ), o espessamento em $U$ apresentou maior desenvolvimento, quando comparado com o dos tratamentos alagados sem ou com adição de cálcio, no qual observa-se ainda que as células em frente ao protoxilema não se espessam, apresentando apenas estrias de Caspary. Essas células são chamadas células de passagem (Figuras $1 \mathrm{O}$ e 1P). Assim, pode-se deduzir que o alagamento tem uma influência direta no espessamento da endoderme.

No sistema vascular, as raízes dos tratamentos sob irrigação normal sem ou com adição de cálcio (Figuras 1I e 1J) apresentaram o periciclo mais largo e o parênquima medular com maior diâmetro quando comparados com aquelas dos alagados (Figuras 1K e 1L).

A epiderme apresentou-se estatisticamente diferente entre os tratamentos alagados e com irrigação normal (Tabela 1). No entanto, somente os tratamentos com irrigação normal promoveram diferenças entre si, o que leva a concordar com os resultados obtidos por Purcino et al. (2001b), nos quais o cálcio diminuiu o desenvolvimento desse tecido por reduzir o metabolismo. Posteriormente, esse fato auxilia na sobrevivência das plantas de "Saracura" sob alagamento. O diâmetro do cilindro vascular segue a mesma tendência (Tabela 1), não apresentando diferença estatística. 


\section{Conclusão}

Se considerarmos os resultados obtidos, pode-se sugerir que modificações morfoanatômicas imposta pelo cálcio são importantes para explicar a tolerância dessa variedade à inundação.

\section{Literatura Citada}

ALVES, J. D.; MAGALHÃES, M. M.; GOULART, P. F. P.; DANTAS, B. F.; GOUVÊA, J. A.; PURCINO, R. P.; MAGALHÃES, P. C.; FRIES, D. D.; LIVRAMENTO, D. E.; MEYER, L. E.; SEIFFERT, M.; SILVEIRA, T. Mecanismos de tolerância da variedade de milho "Saracura" (BRS 4154) ao alagamento. Revista Brasileira de Milho e Sorgo, Sete Lagoas, v. 1, n. 1, p. 33-40, jan./abr. 2002.

BARUCH, Z.; MÉRIDA, T. Effects of drought and flooding on root anatomy in four tropical forage grasses. International Journal Plant Science, Chicago, v. 156, n. 4, p. 514-521, July 1995.

BUKATSH, F. Benerkungren zur doppelfarbung astrablausafrina. Microkosmos, Stuttgart. v. 61, p. 255, 1972.

DAMARTY, M.; MORUAN, C.; THELLIER, M. Calcium and cell. Plant Cell Environmental, Oxford, v. 7, p. 441-448, 1984.

DANTAS, B. F.; ARAGÃO, C. A.; ALVES, J. D. Cálcio e o desenvolvimento de aerênquimas e atividade de celulase em plâtulas de milho submetidas a hipoxia. Scientia Agrícola, Piracicaba, v. 58, p. 251-257, abr.jun. 2001.

DREW, M. C.; JACKSON, M. B.; GIFFARD, S. Ethylene-promoted adventitious rooting and development of cortical air spaces (aerenchyma) in roots may be adaptive responses to flooding in
Zea mays L. Planta, Berlin, v. 147, n. 1, p. 8388, 1979.

DREW, M. V. Oxigem deficiency and root metabolism: injury and acclimatation under hypoxia and anoxia. Annual Review of Plant Physiology and Plant Molecular Biology, Palo Alto, v. 48, p. 223-250, 1997.

DURBIN, R. D. Abiotic diseases induced by unfavorable water relations. In: KOZLOWSKI, T. T. Water déficits and plant growth. New York: Academic Press, 1971. v. 5: Water and Plant Disease.

EMPRAPA. Centro Nacional de Pesquisa de Solo. Sistema brasileiro de classificação de solos. Rio de Janeiro, 1999. 412 p.

ESAU, K. Anatomia das plantas com sementes. 12.ed. São Paulo: Edgard Blücher, 1993. 293 p.

GRANT, G. T.; MORRIS, D. A.; REES, P. J. P.; SMITH, K. A. Biological interactions between polysaccharides and divalent cations: The eggbox model. FEBS Letters, Amsterdam, v. 32, n. 1, p. 195-198, 1973.

HAYS, K. L.; BARBER, J. G.; KENNA, M. P.; McCOLLUM, T. G. Drougght avoidance mechanisms of seleted bermudagrass genotypes. HortScience, Alexandria, v. 26, n. 2, p. 180-182, Feb. 1991.

HUANG, B.; FRY, J. D. Root anatomical physiological, and morphological to drought stress for tall fescue cultivars. Crop science, Madison, v. 38, n. 4, p. 1017-1022, July/Aug. 1998

HUANG, B.; JHONSON, J. W.; NeSMITH, T. S.; BRIDGES, D. C. Nutrient accumulation and distribution of wheat genotypes in response to 
waterlogging and nutrient supply. Plant and Soil, Dordrecht, v. 173, n. 1, p. 47-54, June 1995.

JOHANSEN, D. A. Plant microtechnique. 2.ed. New York: Mc Graw-Hill, 1940. 523 p.

JACKSON, M. B.; DREW, M. C. Effects of flooding on growth and metabolism of herbaceous plants. In: KOZLOWSKI, T. T. Flooding and plant growth San Diego: Academic Press, 1984. p. 47-128.

KAWASE, M. Annatomical and morphological adaptation of plants to waterlogging. HortScience, Alexandria, v. 16, p. 30-34, 1987.

KOLB, ROSANA M., MEDRI, MOACYR E., BIANCHINI, EDMILSON et al. Anatomia ecológica de Sebastiania commersoniana (Baillon) Smith \& Downs (Euphorbiaceae) submetida ao alagamento. Rev. bras. Bot. [online]. Dez. 1998, vol.21, no.3 [citado 26 Outubro 2004] Disponível na World Wide Web: <http://www.scielo.br/ scielo.php?script $=$ sci, 84041998000300010 \&lng $=$ pt\&nrm $=$ iso $>$. ISSN 0100-8404

LIVRAMENTO, D. E.; ALVES, J. D.; MAGALHÃES, M. M.; FREITAS, R. B.; MEYER, L. E. Avaliação das trocas gasosas, eficiência fotoquímica e desenvolvimento de plantas de milho (Zea mays L.) submetidas a diferentes regimes de encharcamento do sistema radicular. In: CONGRESSO BRASILEIRO DE FISIOLOGIA VEGETAL, 8., 2001, Ilhéus. Anais...Ilhéus: SBFV, 2001. CD-ROM.

MAGAlHÃES, P. C.; DURÃES, F. O. M.; ANDRADE, C. de L. T. de; OLIVEIRA, A. C. de; GAMA E. E. G. Adaptação do milho a diferentes condições de alagamento. In: CONGRESSO NACIONAL DE MILHO E SORGO, 23, 2000, Uberlândia. [Resumos expandidos]... Sete
Lagoas: ABMS, Embrapa Milho e Sorgo, 2000. CD-ROM.

MENEZES NETO, M. A. Influência da disponibilidade de oxigênio sobre a germinação, crescimento e atividade das enzimas álcool desidrogenase e lactato desidrogenase em açaí (Euterpe oleracea Mart.). 1994. 50 f. Tese (Mestrado) - Escola Superior de Agricultura de Lavras, Lavras.

MORAES, M. G.; ALVES J. D.; OLIVEIRA, L .E. M. Efeito da anaerobiose induzida por alagamento em plântulas de seis espécies herbáceas. Ciência e Agrotecnologia, Lavras, v. 25, n. 4, p. 941-951, jul./ago. 2001.

PARENTONI, S. N.; GAMA, E. E. G.; MAGNAVACA, R.; MAGALHÃES, P. C. selection for tolerance to waterloggins in maize (Zea mays L.). In: SIMPÓSIO INTERNACIONAL SOBRE ESTRESSE ABIÓTICO, 1995, Belo Horizonte. Anais... Belo Horizonte - MG. 1995. p. 434-449.

PLATZECK, C. O. Efeito da inundação sobre o establecimento de Brachiaria humidicola (Rendle) Schweickerdt e Setaria anceps Stapf ex Massey c.v. Kazungula. 1989. 163 f. Tese (Mestrado) - Escola Superior de Agricultura "Luiz de Queiroz", Universidade de São Paulo, Piracicaba.

PURCINO, R. P.; ALVES, J. D.; MAGALHÃES, M. M.;SILVEIRA, T.; FRIES, D. Efeito do cloreto de cálcio na germinação de sementes de milho da variedade BR-154 "Saracura" In: CONGRESSO BRASILEIRO DE FISIOLOGIA VEGETAL, 8., 2001, Ilhéus. Anais... Ilhéus: SBFV, 2001a. CD-ROM.

PURCINO, R. P.; ALVES, J. D.; MAGALHÃES, M. M.;SILVEIRA, T.; FRIES, D. Efeito fisiológico 
do cálcio na germinação de sementes de milho da BR-154 "Saracura" e na tolerância das plântulas ao alagamento. In: CONGRESSO BRASILEIRO DE FISIOLOGIA VEGETAL, 8.,2001, Ilhéus. Anais... Ilhéus: SBFV, 2001 b. CD-ROM.

SAAB, I. N.; SACHS, M. M. A flooding induced xyloglucan endo-transglycosylase homolog in maize is responsive to ethylene and associated with aerenquima. Plant Physiology, Bethesda, v. 112, p. 385-391, 1996.

SELING, S.; WISSEMEIER, A. H.; CAMBIER, P.; CUTSEM, P. V. Calcium deficiency in potato (Solanum tuberosum ssp. tuberosum) leaves and its effects on the pectic composition of the apoplastic fluid. Physiologia Plantarum, Copenhagen, v. 109, p. 44-50, 2000.

SEAGO, J. L.; MARSH, L. C. Adventitious root development in Thypha glauca whit emphasis on the cortex. American Journal of Botany, Bronx, v. 76, p. 909-923, 1989.

SILVA, S; CASTRO, E. M.; SOARES, A. M. Efeito de diferentes regimes hídricos sobre características anatômicas de raiz de gramíneas promissoras para revegetação ciliar de reservatórios hidrelétricos. Ciência e Agrotecnologia, Lavras, v. 27, n. 2, p. 393-397, 2003.

SUBBAIAH, C. C.; BUSH, D. S.; SACHS, M. M. Elevation of cytosolic calcium precedes anoxic gene expression in maize suspension cultured cells. The Plant Cell, Rockville, v. 6, p. 1747-1762, 1994.

VITORINO, P. G.; ALVES, J. D.; MAGALHÃES, P. C.; MAGALHÃES, M. M.; LIMA, L. C. O.; OLIVEIRA, L. E. M. Flooding tolerance and cell wall alterations in maize mesocotyl during hypoxia. Pesquisa Agropecuaria Brasileira, Brasilia, v. 36, n. 8, p. 1027-1035, ago. 2001. 